J. Dairy Sci. 99:9521-9533

http://dx.doi.org/10.3168/jds.2016-11585

(C) 2016, THE AUTHORS. Published by FASS and Elsevier Inc. on behalf

of the American Dairy Science Association ${ }^{\circledR}$. This is an open access article under

the CC BY-NC-ND license (http://creativecommons.org/licenses/by-nc-nd/3.0/).

\title{
Variability in chemical and microbiological profiles of long-ripened Caciocavallo cheeses
}

\author{
Mariantonietta Succi, ${ }^{*}$ Maria Aponte, $†$ Patrizio Tremonte, ${ }^{* 1}$ Serena Niro, ${ }^{*}$ Elena Sorrentino, ${ }^{*}$ \\ Massimo lorizzo, ${ }^{*}$ Luca Tipaldi, ${ }^{*}$ Gianfranco Pannella, ${ }^{*}$ Gianfranco Panfili, ${ }^{*}$ Alessandra Fratianni, ${ }^{*}$ \\ and Raffaele Coppola* \\ *Department of Agricultural, Environmental and Food Sciences (DiAAA), University of Molise, 86100 Campobasso, Italy \\ †Department of Agricultural Sciences, University of Naples Federico II, 80055 Portici, NA, Italy
}

\begin{abstract}
Five protected designation of origin (PDO) Caciocavallo Silano and 6 non-PDO Caciocavallo cheeses, ripened for 6 mo and collected in the 5 Italian regions of the PDO area (Apulia, Basilicata, Calabria, Campania, and Molise, Italy), were studied to assess their physicochemical ( $\mathrm{pH}$, acidity, moisture, fat, ash, protein, and free amino acid composition) and microbiological profiles. Analyses evidenced a certain fluctuation of previous parameters among samples regardless of the kind of cheese evaluated (PDO and non-PDO). The PCR-denaturing gradient gel electrophoresis analysis performed on the DNA directly extracted from cheeses gave different results, but a low number of bands was always observed. Only one band, corresponding to the species Streptococcus thermophilus, was detectable in 1 $\mathrm{PDO}$ and in 2 non-PDO cheese samples, whose free amino acid content was the lowest. Analyses were repeated on experimental Caciocavallo cheeses. Specifically, 2 productions were made, one mimicking the industrial technology (pasteurized milk and selected starter culture) and one the artisanal technology (raw milk and natural whey starter). Results obtained on experimental cheeses at 6 mo of ripening showed that industrial samples had lower amounts of total free amino acids then the artisanal ones $(1,188.2$ vs. $7,523.67 \mathrm{mg} / 100 \mathrm{~g}$ of dry matter). Moreover, the PCR-denaturing gradient gel electrophoresis analysis evidenced the sole presence of $S$. thermophilus in the case of the industrial technology. These data sustain the hypothesis that, out of 11 cheeses analyzed previously, 1 PDO Caciocavallo Silano and 2 non-PDO Caciocavallo cheeses were obtained with the industrial technology. These results could be
\end{abstract}

Received June 10, 2016.

Accepted August 24, 2016.

${ }^{1}$ Corresponding author: tremonte@unimol.it of help in the discrimination of PDO products, taking into account that the PDO production regulation does not allow the milk pasteurization, nor the use of selected starters.

Key words: pasta filata cheese, free amino acid, natural whey starter, Streptococcus thermophilus

\section{INTRODUCTION}

The Southern Italian dairy industry produces a wide variety of fresh and ripened pasta filata cheeses. Among them, the term "Caciocavallo" is used to describe a semi-hard pasta filata cheese historically produced in various Italian regions. In 1993, some Southern Italian producers founded the Caciocavallo Silano Consortium, and in 1996 the cheese obtained the protected designation of origin (PDO; European Union, 1996). Currently, the consortium includes 23 manufacturers, and the PDO area of production reaches an area of 51,609 $\mathrm{km}^{2}$ (the second largest in Italy after that of the PDO Grana Padano cheese; European Union, 2003), including 5 Italian regions (Apulia, Basilicata, Calabria, Campania, and Molise).

The PDO Production Regulation for Caciocavallo Silano allows the sole use of raw bovine milk, eventually thermized up to $58^{\circ} \mathrm{C}$ for $30 \mathrm{~s}$ (under the obligation to report this treatment on the label), and only natural whey starter (NWS) prepared in the same dairy plant of transformation is permitted. The minimum ripening period is $1 \mathrm{mo}$, but it may last up to $1 \mathrm{yr}$ and even longer. On the other hand, in the same production area of the PDO Caciocavallo Silano cheese, there is a widespread presence of dairy plants devoted to the production of Caciocavallo cheeses that assume different denominations, such as Caciocavallo Molisano (from Molise region), Caciocavallo Pugliese (from Apulia region), Caciocavallo Campano (from Campania region), and so on, depending on the geographical origin. These 
non-PDO Caciocavallo cheeses can be produced with different technologies and ingredients, with a subsequent generation of cheeses sharing only a few features.

Several studies have focused on the microbial or biochemical characteristics (or both) of Caciocavallo cheeses from Southern Italy (Coppola et al., 2003; Marotta et al., 2007; Morea et al., 2007), highlighting differences among apparently similar products. For instance, Piraino et al. (2005) found a high diversity in the proteolytic pattern of PDO Caciocavallo Silano cheeses analyzed at different ripening times, whereas Morea et al. (2007) and Di Cagno et al. (2012) reported meaningful differences in the free amino acid (FAA) profile and in the load of lactobacilli in Caciocavallo cheeses produced in a particular Italian region (Apulia).

Whereas numerous studies demonstrated the influence of starter cultures on different parameters of ripened pasta filata cheeses (Ercolini et al., 2008; Di Cagno et al., 2012; Aydemir et al., 2015; Gobbetti et al., 2015), only a few reports described the influence of milk treatments on some physico-chemical parameters of Caciocavallo cheese (Albenzio et al., 2010). In addition, to our knowledge, no research compared the physico-chemical and microbiological profiles of long-ripened Caciocavallo cheeses produced with the artisanal [raw milk (RM) and NWS] and the industrial [pasteurized milk (PM) and selected starter cultures] technology.

In light of the previous findings, this work was divided in 2 steps. First, the physico-chemical and microbiological characteristics of 5 PDO Caciocavallo Silano and 6 non-PDO Caciocavallo cheeses, all at the same stage of ripening (6 mo), were investigated. Then, the data obtained were compared with those acquired by 2 experimental productions of artisanal and industrial Caciocavallo cheeses with the aim to detect the presence of measurable parameters allowing the differentiation between the 2 production technologies.

\section{MATERIALS AND METHODS}

\section{Sampling of Caciocavallo Cheeses}

Five PDO Caciocavallo Silano cheese samples at 6 mo of ripening, with the typical "fire mark" PDO designation impressed on the surface, were collected from dairy plants located in the 5 Italian regions of the designated PDO area (Apulia, Basilicata, Calabria, Campania, and Molise). Six non-PDO Caciocavallo cheeses at 6 mo of ripening were obtained in the same sampling area. At the purchasing moment, all the 11 producers declared the age of cheeses $(6 \mathrm{mo})$ and the production according to the artisanal technology.
The PDO Caciocavallo Silano cheeses were labeled based on their geographical origin, as follows: PDOApu1 (Apulia), PDOBas1 (Basilicata), PDOCal1 (Calabria), PDOCam1 (Campania), and PDOMol1 (Molise). Analogously, the non-PDO Caciocavallo cheeses were designated Apu2 (Apulia), Bas2 (Basilicata), Cal2 (Calabria), Cam2 and Cam3 (Campania), and Mol2 (Molise). Samples were transported to the laboratory at refrigerated temperature and analyzed within a maximum of $5 \mathrm{~h}$.

\section{Physico-Chemical Analyses}

Titratable acidity (TA; AOAC International, 2000; method 920.124), moisture (AOAC International, 2000; method 948.12), fat (AOAC International, 2000; method 933.05), and ash (AOAC International, 2000; method 935.42) were evaluated for each sample. Cheese $\mathrm{pH}$ was measured using a $\mathrm{pH}$ meter (Crison 2001 series; Crison Instruments, Barcelona, Spain) as described by Niro et al. (2014). Total protein was determined by the Kjeldahl method (AOAC International, 2000; method 920.123); FAA were analyzed by using a Biochrom 30 series Amino Acid Analyzer (Biochrom Ltd., Cambridge, UK) with a Li-cation-exchange column (20 $\mathrm{cm} \times 0.46 \mathrm{~cm})$. Samples were prepared as described by Bütikofer and Ardö (1999).

\section{Microbiological Analyses}

Ten grams of each cheese was homogenized with 90 $\mathrm{mL}$ of sterile quarter-strength Ringer's solution (Oxoid, Milan, Italy) in a blender (Stomacher 400, Seward Medical, London, UK), and 10-fold dilutions were made in the same diluent. Dilutions from each sample were pour plated in duplicate in de Man, Rogosa, Sharpe agar (Oxoid) and M17 agar (Oxoid). Incubation was carried out at 22 and $45^{\circ} \mathrm{C}$ to count both viable mesophilic and thermophilic/thermotolerant lactic acid bacteria (LAB; Coppola et al., 2000, 2001). Results were expressed as the mean \pm standard deviation of 2 determinations.

\section{PCR-Denaturing Gradient Gel Electrophoresis Analysis}

The DNA extraction from cheese samples was performed according to the method described by Iacumin et al. (2009). Primers used in this study were P1V1 (5'-GCGGCGTGCCTAATACATGC-3'; Cocolin et al., 2001) and P2V1 (5'-TTCCCCACGCGTTACTCACC-3'; Rantsiou et al., 2005). A GC clamp (Sheffield et al., 1989) was attached to the $5^{\prime}$ end of the P1V1 primer. 
Amplifications were carried out in a Mastercycler gradient (Eppendorf, Hamburg, Germany). Five microliters of each PCR mixture was analyzed by electrophoresis in a $0.5 \times$ Tris-borate-EDTA agarose gel, and denaturing gradient gel electrophoresis (DGGE) analysis was performed as described by Iacumin et al. (2009). The Dcode Universal Mutation Detection system (Bio-Rad, Hercules, CA) was used. The DGGE-PCR profiles were obtained directly using the digital camera ImageMaster VDS software (Amersham Pharmacia Biotech, Milan, Italy). For comparative purposes, the DNA of different LAB type strains (obtained from Deutsche Sammlung von Mikroorganismen und Zellkulturen GmbH, Braunschweig, Germany) were subjected to DGGE analysis as described by Reale et al. (2013) and used as an internal database. Gels were then normalized as described by Succi et al. (2014).

\section{Experimental Production of Caciocavallo Cheeses}

Two different productions of Caciocavallo cheese were performed in a pilot plant located at the Scientific and Technological Park of Molise. Specifically, 200 L of raw bovine milk from 2 daily milkings was equally divided into 2 batches. One batch was used for the production of Caciocavallo cheese according to the artisanal practice (RM and NWS), following the indications of the PDO production regulation for Caciocavallo Silano cheese. Briefly, raw bovine milk was heated at $37^{\circ} \mathrm{C}$, inoculated with $3 \%$ (vol/vol) of NWS, kindly provided by Caseificio Molisano Barone (Vinchiaturo, Campobasso, Italy), and added to a commercial liquid calf rennet (40 mL/100 L; Clerici-Sacco Group, Cadorago, Italy). Coagulation took place within 35 to $40 \mathrm{~min}$. The coagulum was first cut by hand, held under whey $\left(37^{\circ} \mathrm{C}\right)$ for about $2 \mathrm{~h}$, and then reduced to particles of 1.5 to 2 $\mathrm{cm}$. After whey removal, the curd was placed on tables until the $\mathrm{pH}$ reached a value suitable for stretching in hot water at $80^{\circ} \mathrm{C}$ (about $6 \mathrm{~h}$ ). Cheeses were salted in brine $(30 \% \mathrm{wt} / \mathrm{vol} \mathrm{NaCl})$ for $12 \mathrm{~h}$ and then placed in a ripening chamber $\left(15^{\circ} \mathrm{C}\right.$ and $83 \%$ relative humidity) for $180 \mathrm{~d}$ (Mincione et al., 1996).

The second batch of milk was used for the production of Caciocavallo cheese following the industrial practice $[\mathrm{PM}$ and commercial starter culture (SC)]. The industrial manufacture was performed as reported above, except that PM $\left(71^{\circ} \mathrm{C}\right.$ for $\left.15 \mathrm{~s}\right)$ cooled at $37^{\circ} \mathrm{C}$ was used, and a SC, composed of Streptococcus thermophilus and Lactobacillus delbrueckii ssp. bulgaricus (CSL, Lodi, Italy), was added following the supplier's instructions.

Another identical set of experimental cheese production was repeated after $1 \mathrm{wk}$. Ten cheeses, about $1.5 \mathrm{~kg}$ each, were obtained by each production. The $\mathrm{pH}$, TA, and FAA content was determined as described previously.

\section{LAB Evolution During Experimental Manufacture}

Samples of RM and PM, NWS, and SC, bulk milk added with NWS or SC, mature curd, pasta filata, Caciocavallo cheeses immediately after production (CV0) and after 6 mo of ripening (CV6) were collected during the experimental productions of Caciocavallo cheeses. The LAB counts were carried out as previously detailed. The DNA extraction and amplification, as well as band detection for PCR-DGGE analysis, were performed according to the protocol previously described. For comparative purposes, the DNA of $S$. thermophilus and $L b$. delbrueckii ssp. bulgaricus, previously isolated from the SC, was subjected to DGGE analysis.

\section{Statistical Analysis}

The ANOVA was applied to the physico-chemical data. The least significant differences were obtained using a least significant difference test $(P<0.05)$. Statistical analysis was performed using SPSS version 13.0 for Windows (SPSS Inc., Chicago, IL).

\section{RESULTS AND DISCUSSION}

\section{Evaluation of PDO and Non-PDO Caciocavallo Cheeses}

Values of physico-chemical parameters and gross composition for the 11 cheeses at 6 mo of ripening are reported in Table 1. Generally, the analysis of data did not allow a distinction between PDO and non-PDO cheeses due to a certain fluctuation, more or less pronounced, in the assayed parameters. Specifically, with the sole exception of sample PDOApu1, $\mathrm{pH}$ values did not significantly differ and appeared to be in agreement with those previously reported by Marotta et al. (2007). A higher variability was recorded for TA, showing values ranging from $0.30 \pm 0.01$ to $0.48 \pm$ $0.07 \mathrm{~g} / 100 \mathrm{~g}$ of lactic acid in PDOCam1 and Cam3, respectively. Significant differences $(P<0.05)$ were highlighted for moisture, protein, fat, and ash content. Moisture showed a significant variability, with the highest value in Mol2 (36.8\%) and the lowest one in Apu2 (24.7\%), probably due to different ripening conditions. Caciocavallo cheese is traditionally produced by a ripening phase that does not include the control of the air flow or relative humidity (\%) levels, leading to different characteristics of final products, as already reported by Niro et al. (2012) and Sorrentino et al. (2013). 
Table 1. Physico-chemical parameters of 5 protected designation of origin (PDO) Caciocavallo Silano and 6 non-PDO Caciocavallo cheeses at 6 mo of ripening

\begin{tabular}{|c|c|c|c|c|c|c|}
\hline Sample $^{1}$ & $\mathrm{pH}$ & Titratable acidity $^{2}$ & Moisture (\%) & $\begin{array}{c}\text { Ash } \\
(\% \text { of DM) }\end{array}$ & $\begin{array}{l}\text { Protein } \\
\text { (\% of DM) }\end{array}$ & $\begin{array}{c}\text { Fat } \\
(\% \text { of DM) }\end{array}$ \\
\hline PDOApu1 & $5.75 \pm 0.00^{\mathrm{b}}$ & $0.40 \pm 0.01^{\mathrm{ab}}$ & $30.51 \pm 0.02^{\mathrm{a}}$ & $6.60 \pm 0.03^{\mathrm{b}}$ & $41.21 \pm 0.04^{\mathrm{a}}$ & $52.00 \pm 0.10^{\mathrm{d}}$ \\
\hline Bas2 & $5.55 \pm 0.02^{\mathrm{a}}$ & $0.36 \pm 0.05^{\mathrm{b}}$ & $30.00 \pm 0.02^{\mathrm{a}}$ & $6.31 \pm 0.02^{\mathrm{ab}}$ & $49.70 \pm 0.01^{\mathrm{d}}$ & $43.83 \pm 0.02^{\mathrm{b}}$ \\
\hline PDOCal1 & $5.48 \pm 0.01^{\mathrm{a}}$ & $0.44 \pm 0.03^{\mathrm{a}}$ & $33.72 \pm 0.10^{\mathrm{b}}$ & $7.43 \pm 0.03^{\mathrm{c}}$ & $43.62 \pm 0.05^{\mathrm{b}}$ & $46.82 \pm 0.02^{\mathrm{c}}$ \\
\hline $\mathrm{Cal} 2$ & $5.52 \pm 0.02^{\mathrm{a}}$ & $0.36 \pm 0.01^{\mathrm{b}}$ & $34.00 \pm 0.04^{\mathrm{b}}$ & $9.93 \pm 0.02^{\mathrm{e}}$ & $46.23 \pm 0.02^{\mathrm{c}}$ & $43.84 \pm 0.03^{\mathrm{b}}$ \\
\hline Cam3 & $5.43 \pm 0.07^{\mathrm{a}}$ & $0.48 \pm 0.07^{\mathrm{a}}$ & $33.71 \pm 0.03^{\mathrm{b}}$ & $9.74 \pm 0.01^{\mathrm{e}}$ & $46.62 \pm 0.04^{\mathrm{c}}$ & $43.52 \pm 0.02^{\mathrm{b}}$ \\
\hline PDOMol1 & $5.52 \pm 0.00^{\mathrm{a}}$ & $0.32 \pm 0.03^{\mathrm{b}}$ & $26.90 \pm 0.01^{\mathrm{c}}$ & $5.81 \pm 0.02^{\mathrm{a}}$ & $43.30 \pm 0.01^{\mathrm{b}}$ & $50.20 \pm 0.02^{\mathrm{d}}$ \\
\hline Mol2 & $5.40 \pm 0.01^{\mathrm{a}}$ & $0.32 \pm 0.01^{\mathrm{b}}$ & $36.80 \pm 0.02^{\mathrm{d}}$ & $10.90 \pm 0.03^{\mathrm{f}}$ & $43.00 \pm 0.00^{\mathrm{b}}$ & $46.00 \pm 0.03^{\mathrm{c}}$ \\
\hline
\end{tabular}

${ }^{\mathrm{a}-\mathrm{f}}$ Means within a column with different superscripts differ $(P<0.05)$.

${ }^{1}$ Sample names indicate the cheeses with and without protected designation of origin (PDO) and the geographical origin: PDOApu1 and Apu2, Apulia; PDOBas1 and Bas2, Basilicata; PDOCal1 and Cal2, Calabria; PDOCam1, Cam2, and Cam3, Campania; and PDOMol1 and Mol2, Molise.

${ }^{2}$ Expressed as grams of lactic acid per $100 \mathrm{~g}$ of cheese.

Total proteins ranged from $41.2 \%$ to $49.9 \%$ of DM in PDOApu1 and PDOCam1, respectively; the fat content varied from 52.0 to $41.2 \%$ of DM in the same samples (Table 1). The unevenness in protein and fat contents may be related to several factors, such as the quality of the milk, the breed, and the feeding regimen of the cows, as well as the period of lactation (Marotta et al., 2007). In spite of such variability, values recorded for PDO Caciocavallo Silano samples were in agreement with those reported in the PDO production regulations (European Union, 1996, 2003).

Only 2 pairs of samples (i.e., PDOMol1/Apu2 and Cal2/Cam3) showed very similar values in chemical composition, but a relation with the geographical area of production was not found. In fact, PDOMol1 and Apu2 samples were collected in dairy farms located at the boundary between Molise and Apulia regions (a few kilometers apart), whereas samples Cal2 and Cam3 were collected from dairy farms far from each other.

Free amino acids detected in cheese samples are reported in Table 2. Overall, PDO cheeses had total FAA values higher than those found in non-PDO samples. The sole exception among PDO samples was PDOBas1, having a lower FAA content than that found in the other PDO cheeses. On the other hand, Bas2 and Cam3 were characterized by the highest FAA values among non-PDO samples. In detail, total FAA varied from 7,344.1 (PDOApu1) to 1,314.0 (Apu2) mg/100 g of DM. Glutamic acid, valine, leucine, phenylalanine, lysine, and proline were the main FAA in all samples, confirming results previously obtained by Corsetti et al. (2001). Results reflected different levels of proteolysis within samples: PDOApu1, PDOCal1, PDOMol1, Bas2, and Cam3 were characterized by a stronger proteolysis compared with the other samples. The relative mean percentage of each FAA demonstrated a high variability among cheeses that, in the present study, was not attributable to the different age of cheeses, as reported by Piraino et al. (2005), because all 11 cheese samples analyzed here were at the sixth month of ripening.

The LAB loads are reported in Figure 1. Two standard culture media and 2 incubation temperatures $(22$ and $44^{\circ} \mathrm{C}$ ) were used for the detection of both mesophilic and thermophilic/thermotolerant LAB rods and cocci. Previous surveys on ripened raw milk cheeses, such as Caciocavallo and Parmigiano Reggiano (Coppola et al., 2001, 2003), highlighted that some mesophilic LAB, chiefly lactobacilli, are able to grow at $44^{\circ} \mathrm{C}$, thus representing the thermotolerant-mesophilic LAB, which are typical in this kind of cheese.

Mesophilic rods varied from 6.9 to $5.4 \mathrm{log} \mathrm{cfu} / \mathrm{g}$ in samples Mol1 and Cal2, respectively, whereas mesophilic cocci ranged from 6.3 to $4.8 \mathrm{log} \mathrm{cfu} / \mathrm{g}$ in samples Apu1 and Cam3, respectively (Figure 1A). In both cases, the $\Delta \log$, calculated as difference between the highest and the lowest microbial count, provided a value of 1.5. Similarly, counts registered at $44^{\circ} \mathrm{C}$ on de Man, Rogosa, Sharpe agar ranged from $5.2 \mathrm{log} \mathrm{cfu} / \mathrm{g}$ in Bas2 to 4.0 log cfu/g in Apu2, Cal1, and Cam1, with a $\Delta \log$ of 1.2. M17 counts after incubation at $44^{\circ} \mathrm{C}$ fluctuated from $5.5 \mathrm{log} \mathrm{cfu} / \mathrm{g}$ in Apu1 to $3.8 \mathrm{log} \mathrm{cfu} / \mathrm{g}$ in Cam2, with a $\Delta \log$ of 1.7 (Figure 1B). The LAB counted at $22^{\circ} \mathrm{C}$ were generally higher than those recorded at $44^{\circ} \mathrm{C}$, as previously reported for this cheese (Coppola et al., 2003). Indeed, the predominance of mesophilic LAB during advanced stages of ripening of pasta filata cheeses has been widely pointed out (Coppola et al., 2003; Morea et al., 2007). 


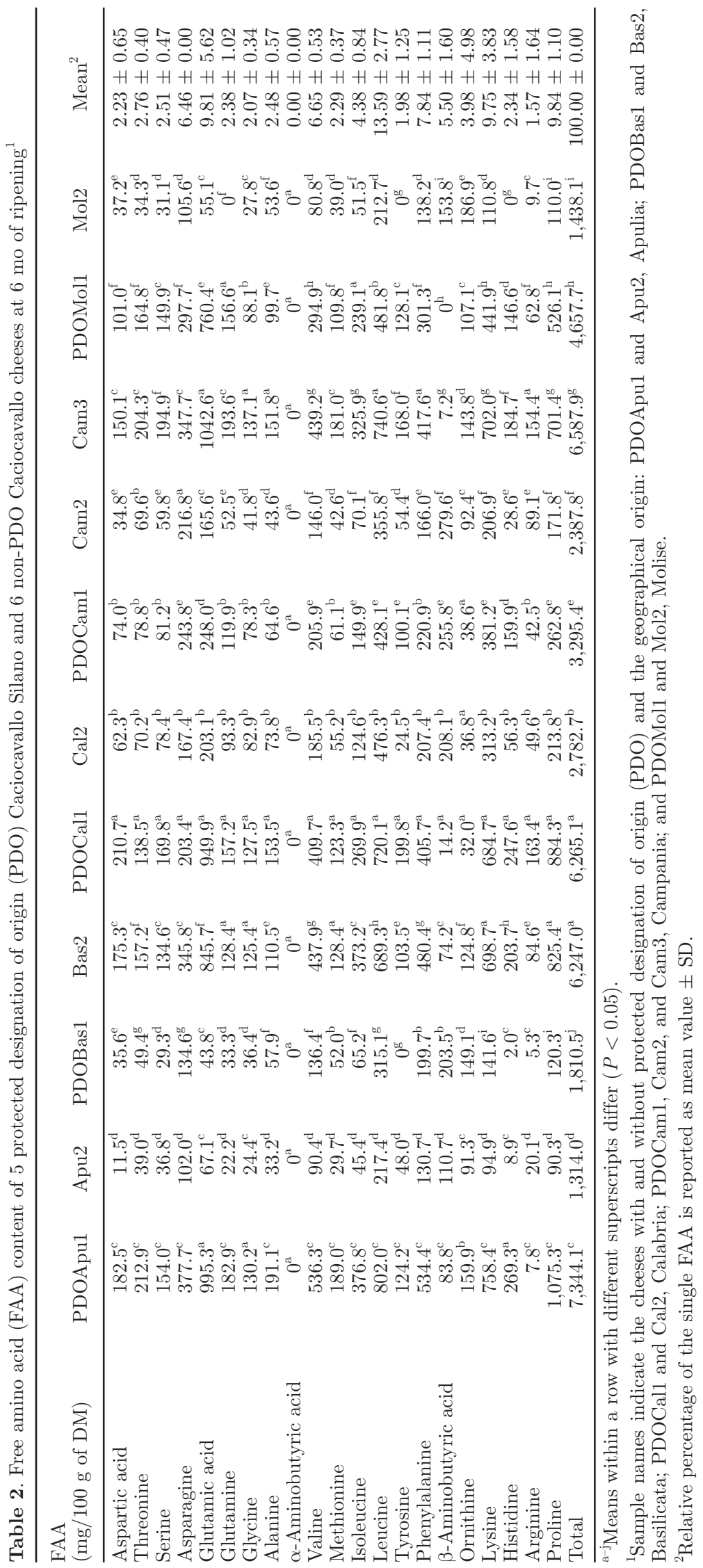



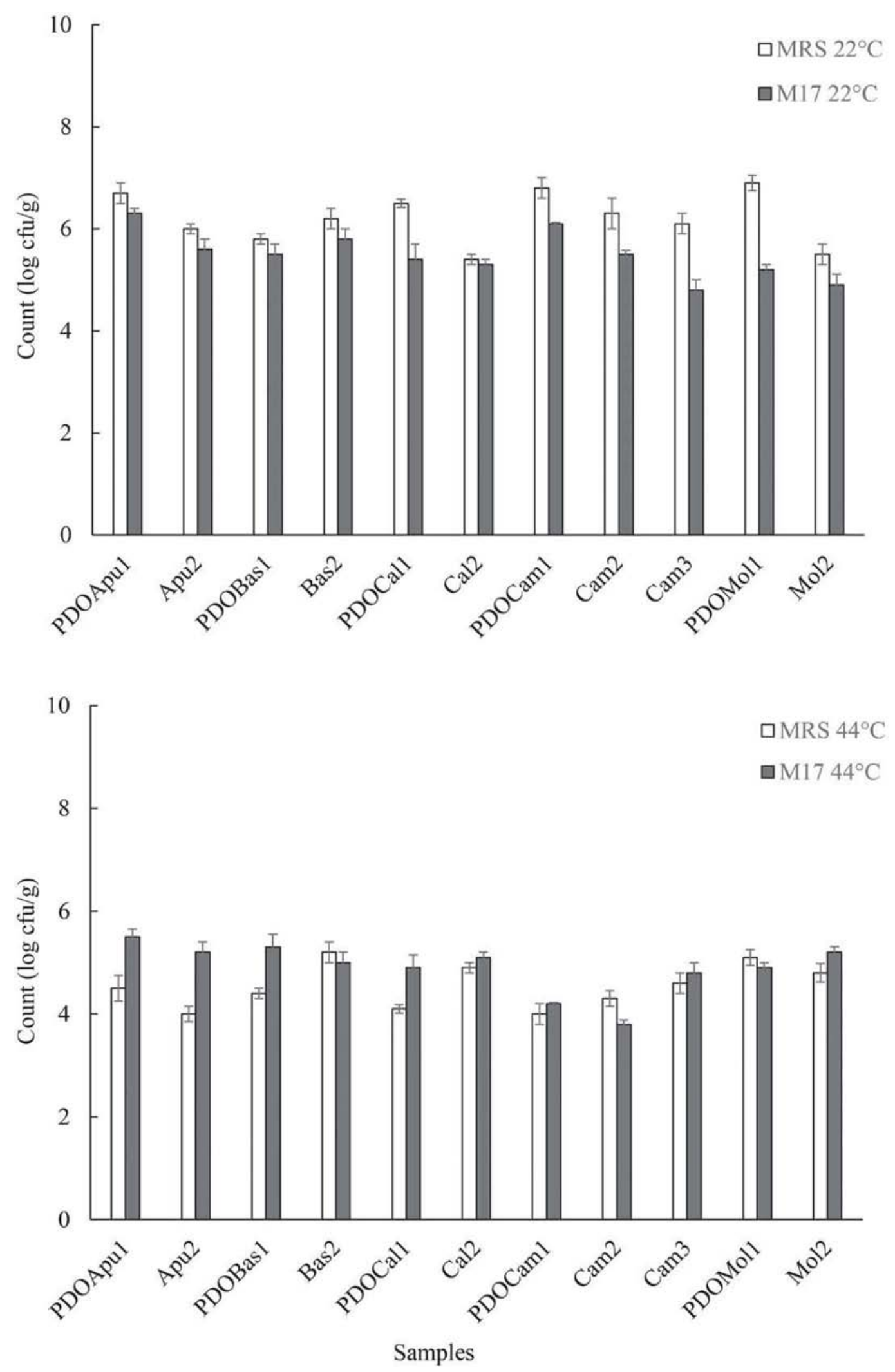

Figure 1. Counts of lactic acid bacteria in 5 protected designation of origin (PDO) Caciocavallo Silano and 6 non-PDO Caciocavallo cheeses at 6 mo of ripening. Values were obtained on de Man, Rogosa, Sharpe (MRS) agar and M17 agar plates after incubation at $22^{\circ} \mathrm{C}(\mathrm{A})$ and $44^{\circ} \mathrm{C}$ (B). The error bars represent the SD calculated on 2 different determinations. 
The microbial biodiversity within cheese samples was evaluated by a culture-independent approach using PCR-DGGE. Analysis of electrophoretic profiles pointed out a low number of bands for all samples, in agreement with outcomes reported by Cocolin et al. (2001). According to these authors, PCR-DGGE analysis on the DNA directly extracted from dairy products usually depicts a high biodiversity in fresh samples, often characterized by complex patterns, whereas DGGE profiles of ripened products consist of just a few bands, corresponding to the species able to dominate the microbial ecosystem. At any rate, remarkable differences among Caciocavallo cheeses were highlighted, with the lowest number of bands in samples Apu2,
PDOBas1, and Mol2 (Figure 2). In all samples, a band co-migrating with that of $S$. thermophilus DSM 20617 was observed. Streptococcus spp. and Lactococcus spp. are considered typical genera characterizing the natural whey starter cultures used in the manufacture of Italian pasta filata cheeses (Parente et al., 1997), so that the presence of species belonging to these genera was proved to be a useful tool to distinguish fresh from ripened Caciocavallo cheeses (Piraino et al., 2005). Unlike this evidence, the presence of Streptococcus spp. in ripened pasta filata cheeses was already detected by other authors. For instance, Aponte et al. (2008) described the prevalence of $S$. thermophilus and Streptococcus macedonicus during the cheese manufacture of Provo-

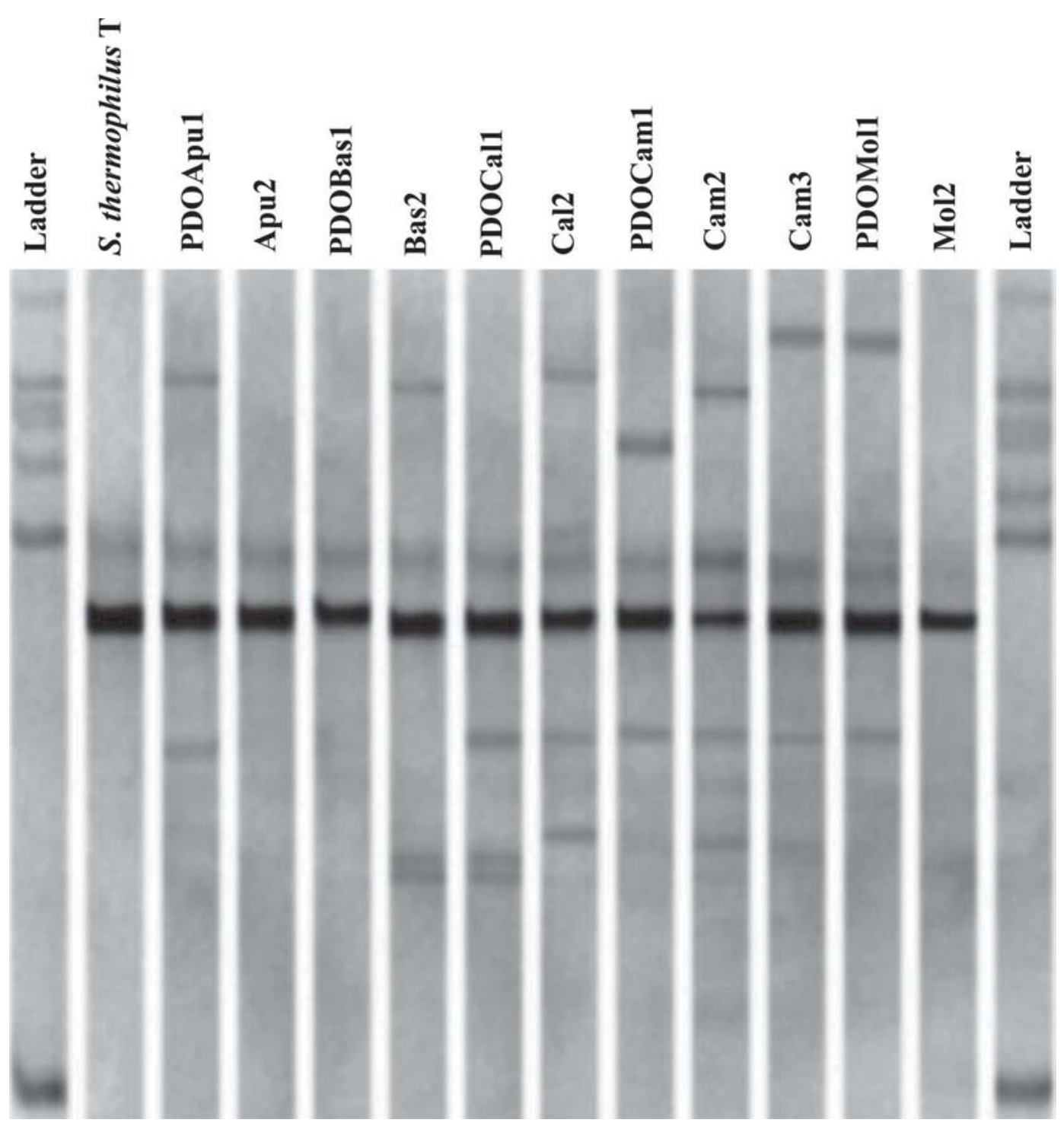

Figure 2. Polymerase chain reaction-denaturing gradient gel electrophoresis of V1 $16 \mathrm{~S}$ rDNA region in 5 protected designation of origin (PDO) Caciocavallo Silano and 6 non-PDO Caciocavallo cheeses at 6 mo of ripening and of Streptococcus thermophilus DSM 20617 ${ }^{\mathrm{T}}$. 
lone del Monaco cheese, and their survival through 9 mo of ripening. Moreover, De Pasquale et al. (2014) showed that the microbial community of Caciocavallo Pugliese cheese, including $S$. thermophilus, is naturally selected during the middle ripening, thus generating a core microbiota mainly responsible for the cheese ripening.

Interestingly, cheese samples characterized by only one band corresponding to that of $S$. thermophilus (Apu2, PDOBas1, and Mol2), were also characterized by the lowest FAA content (Table 2). Because different FAA profiles can suggest a different influence of microbial consortia on the cheese proteolysis (Piraino et al., 2005), microbial involvements during the production and the ripening of the Caciocavallo cheeses under analysis appeared to be different as well.

\section{Experimental Production of Caciocavallo Silano Cheese}

To investigate the role of different production technologies on microbiological and physico-chemical features of ripened Caciocavallo cheese, 2 experimental productions were made: one with PM and selected starter culture (industrial technology) and one with RM and NWS (artisanal technology). In this context, it is important to highlight that the manufacturing of fresh and ripened pasta filata cheeses involves the typical step of stretching, which requires the addition of hot water $\left(80\right.$ to $95^{\circ} \mathrm{C}$ ) to the mature curd (Mucchetti and Neviani, 2006). The time required for the optimal stretching is established by the cheese-maker, and the resulting heat treatment is comparable to that obtained by milk pasteurization. Consequently, the stretching process, as is the pasteurization, will cause the reduction in the number of microorganisms (both contaminant and added with the starter), as well as the inactivation/degradation of heat-labile components, such as proteins or enzymes. Thus, although these last modifications can be used as heat-treatment indicators in milk and in many cheeses, they may not be applied to individuate cheese milk pasteurization in stretched cheeses, as in the case of Caciocavallo cheese (Egger et al., 2016). For this reason, the features of PDO and non-PDO Caciocavallo cheeses described earlier were compared with those of 2 experimental productions, whose the only differences were the milk treatment (raw or pasteurized) and the starter culture (natural or commercial starter). Data regarding the $\mathrm{pH}$ values (Table 3) did not reveal remarkable differences among samples obtained according to the 2 different protocols. As expected, only the NWS showed a $\mathrm{pH}$ significantly different (3.90) from that of the other samples, but fully fitting the typical values registered in other natural whey starters used for the production of Caciocavallo cheeses (Parente et al., 1997). Titratable acidity (Table 3 ) did not differ between the 2 kinds of production, even though higher values were registered in the artisanal Caciocavallo cheeses at 6 mo of ripening (CV6). At any extent, $\mathrm{pH}$ and $\mathrm{TA}$ recorded in the experimental cheeses after 6 mo of ripening matched those recorded in the 11 samples analyzed at first (Table 1).

Table 3. Physico-chemical parameters of Caciocavallo cheeses experimentally produced according to the industrial technology (pasteurized milk and commercial starter culture) and the artisanal technology (raw milk and natural whey starter)

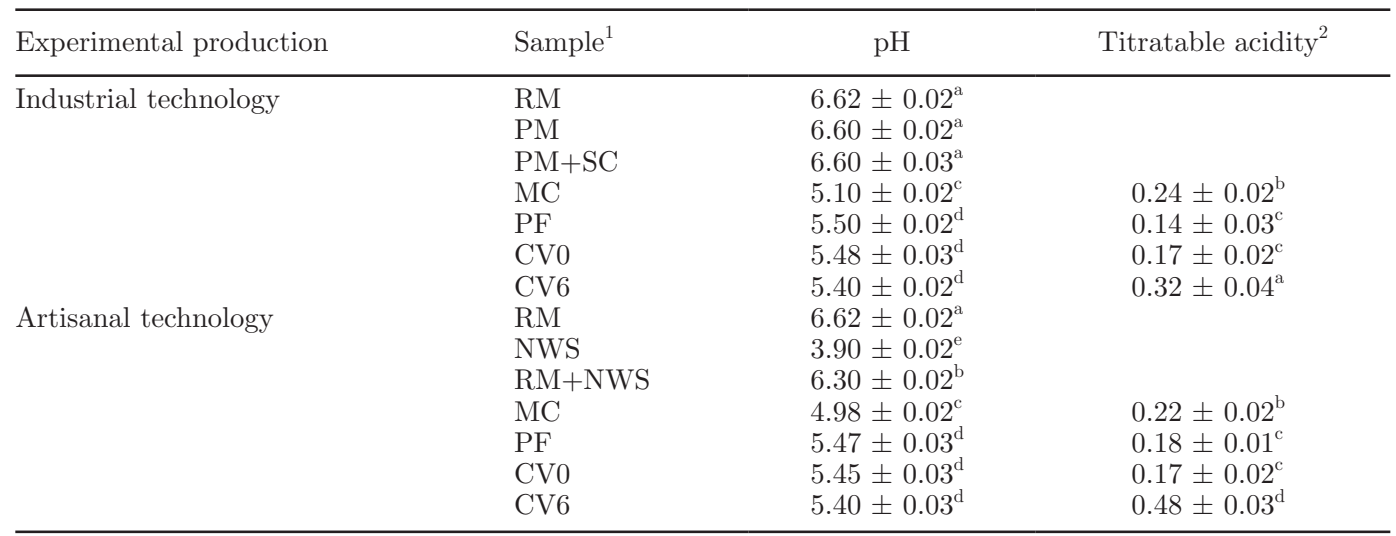

${ }^{\mathrm{a} e}$ Means within a column with different superscripts differ $(P<0.05)$.

${ }^{1} \mathrm{RM}=$ raw milk; $\mathrm{PM}=$ pasteurized milk; $\mathrm{NWS}=$ natural whey starter; $\mathrm{SC}=$ commercial starter culture; $\mathrm{RM}+\mathrm{NWS}=$ bulk milk with NWS added; $\mathrm{PM}+\mathrm{SC}=$ pasteurized milk with $\mathrm{SC}$ added; $\mathrm{MC}=$ mature curd; $\mathrm{PF}=$ pasta filata; $\mathrm{CV} 0=$ cheese after brining; $\mathrm{CV} 6=$ cheese after 6 mo of ripening.

${ }^{2}$ Expressed as grams of lactic acid per $100 \mathrm{~g}$ of cheese. 
The LAB loads varied in the 2 productions during cheese-making and ripening (Figures 3 and 4). Specifically, in samples CV0 and in intermediate samples of the industrial production, mesophilic LAB counts, both rods and cocci, were generally lower (Figures $3 \mathrm{~A}$ and 4A) than those recorded in the artisanal equivalents. By contrast, thermophilic LAB counts were generally lower in the artisanal productions (Figures $3 \mathrm{~B}$ and $4 \mathrm{~B}$ ). However, no significant differences within the $4 \mathrm{LAB}$ groups were detectable in cheeses after 6 mo of ripening (CV6), independently by the production technology, thus jeopardizing the possibility to discriminate industrial from artisanal Caciocavallo cheeses based on LAB loads.

Results regarding the FAA content in experimental productions are reported in Table 4. Caciocavallo cheeses immediately after both productions (CV0) were characterized by similar values in total FAA,
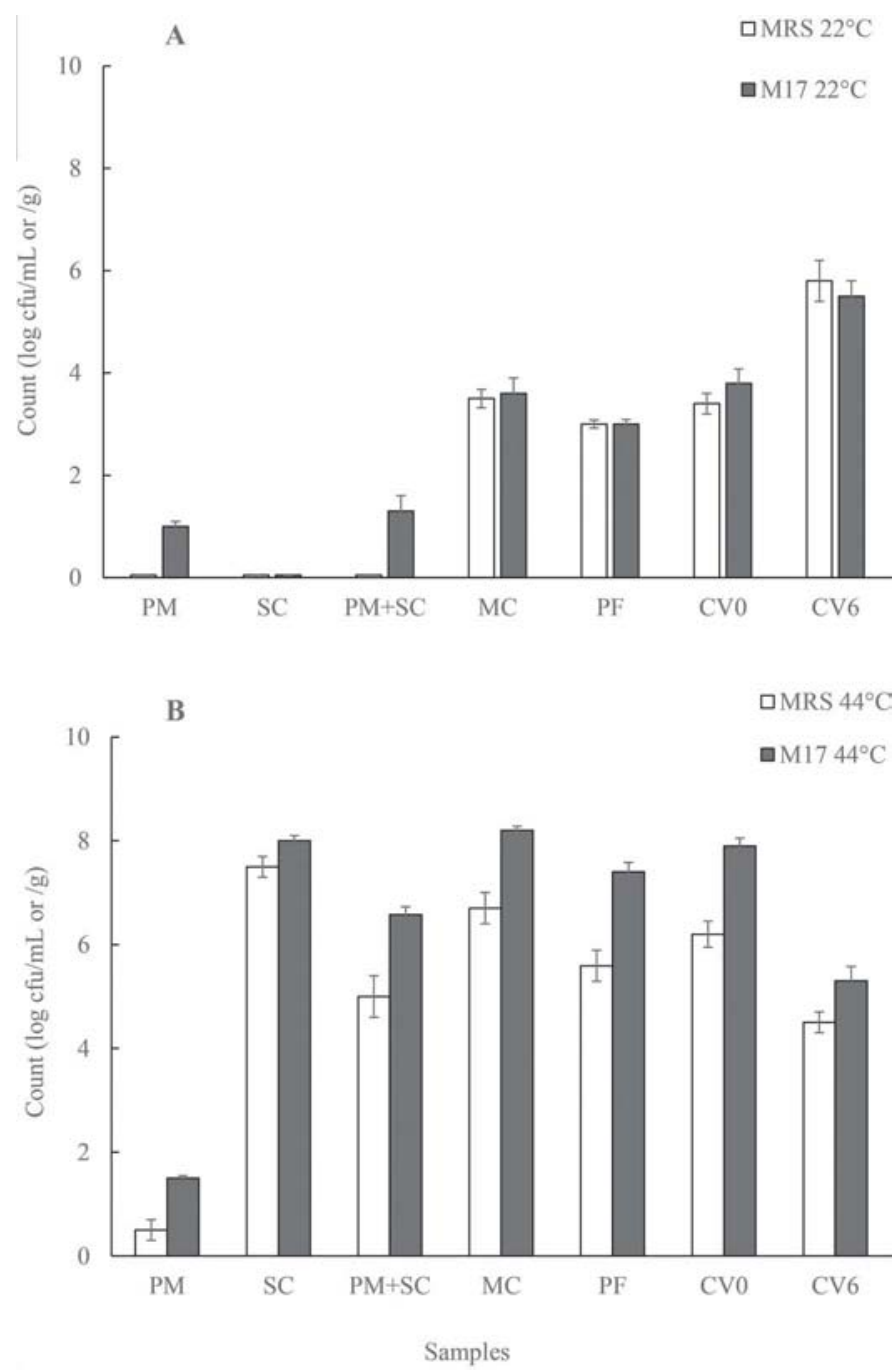

Figure 3. Changes in lactic acid bacteria (LAB) counts during manufacture and ripening of Caciocavallo cheeses experimentally produced according to the industrial technology. Values were obtained on de Man, Rogosa, Sharpe (MRS) agar and M17 agar plates after incubation at $22^{\circ} \mathrm{C}(\mathrm{A})$ and $44^{\circ} \mathrm{C}(\mathrm{B}) . \mathrm{RM}=$ raw milk; $\mathrm{PM}=$ pasteurized milk; NWS = natural whey starter; $\mathrm{SC}=$ commercial starter culture; $\mathrm{RM}+\mathrm{NWS}=$ bulk milk with NWS added; $\mathrm{PM}+\mathrm{SC}=$ pasteurized milk with $\mathrm{SC}$ added; $\mathrm{MC}=$ mature curd; $\mathrm{PF}=$ pasta filata; $\mathrm{CV} 0=$ cheese after brining; CV6 = cheese after 6 mo of ripening. The error bars represent the SD calculated on 2 determinations carried out on 2 different samples analyzed at different times.
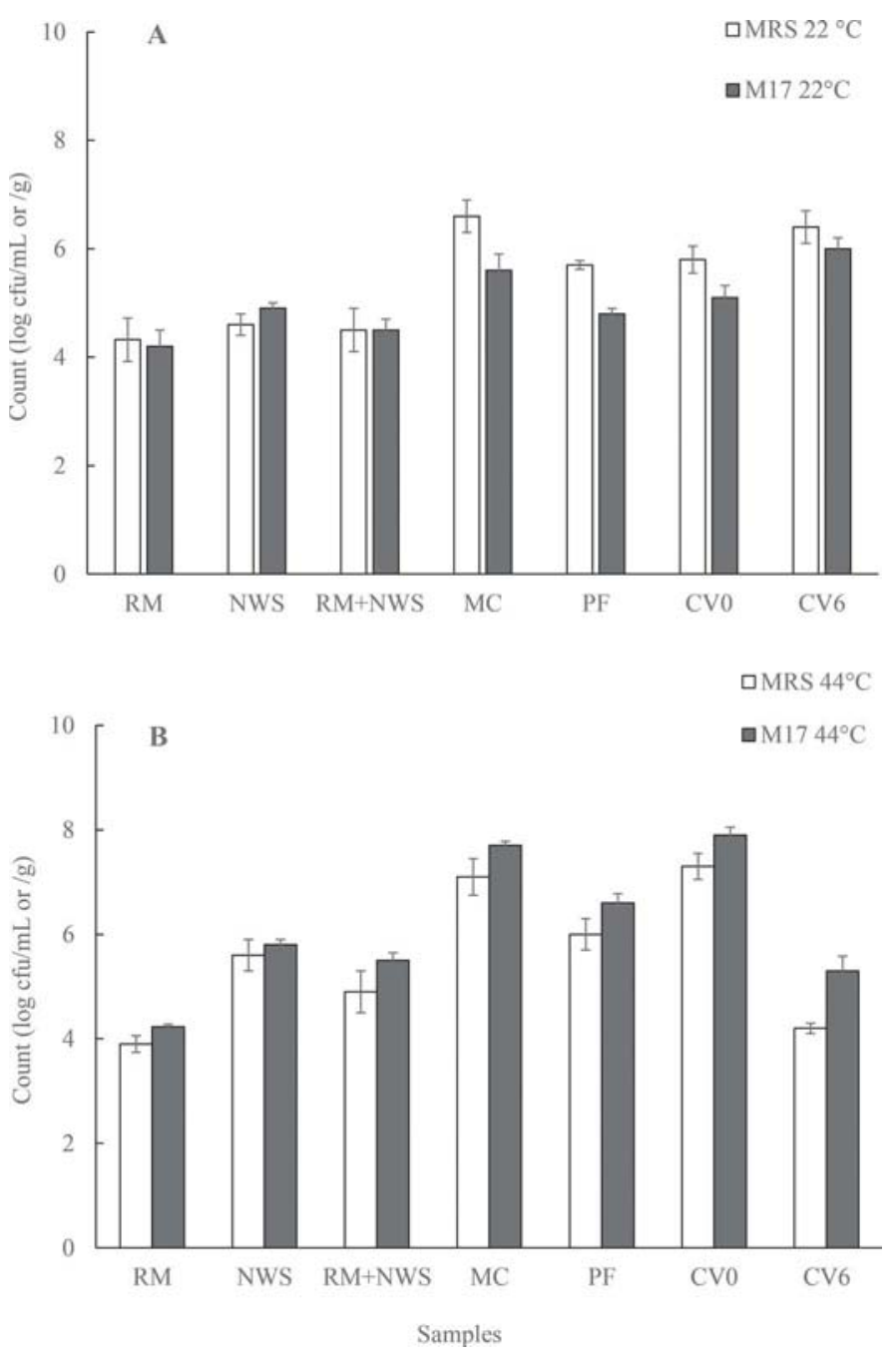

Figure 4. Changes in lactic acid bacteria counts during manufacture and ripening of Caciocavallo cheeses experimentally produced according to the artisanal technology. Values were obtained on de Man, Rogosa, Sharpe (MRS) agar and M17 agar plates after incubation at $22^{\circ} \mathrm{C}(\mathrm{A})$ and $44^{\circ} \mathrm{C}(\mathrm{B}) . \mathrm{RM}=$ raw milk; $\mathrm{PM}=$ pasteurized milk; NWS $=$ natural whey starter; $\mathrm{SC}=$ commercial starter culture; $\mathrm{RM}+\mathrm{NWS}$ $=$ bulk milk with NWS added; PM+SC = pasteurized milk with SC added; $\mathrm{MC}=$ mature curd $; \mathrm{PF}=$ pasta filata $; \mathrm{CV0}=$ cheese after brining; $\mathrm{CV} 6=$ cheese after 6 mo of ripening. The error bars represent the SD calculated on 2 determinations carried out on 2 different samples analyzed at different times. 
whereas values detected in 6-mo ripened cheeses were significantly different: $1,188.2$ and $7,523.67 \mathrm{mg} / 100 \mathrm{~g}$ of DM for cheeses produced by industrial and artisanal technologies, respectively. In detail, total FAA registered in samples Apu2, PDOBas1, and Mol2 (Table 2) were comparable to those reported for CV6 samples made with the industrial technology (Table 3). In these samples, values of glutamic acid, isoleucine, lysine, and histidine were always lower than those recorded in all the remaining samples, including $\mathrm{CV} 6$ made with artisanal technology. By contrast, phenylalanine was higher in samples Apu2, Bas1, Mol2, and CV6 made with industrial technology. Such distinctions are not surprising: according to Grappin and Beuvier (1997), the amount of FAA in cheeses obtained from pasteurized milk is always lower than that of the same kind of cheese produced by using raw milk. Moreover, Piraino et al. (2008) highlighted that nonstarter LAB may exhibit a higher FAA production compared with $S$. thermophilus strains. This evidence was also confirmed by De Pasquale et al. (2014). The FAA evolution during the ripening of cheese made with different technologies (i.e., RM or PM and natural or adjunct cultures) has been previously investigated in different dairy products (Frau et al., 1997; Rehman et al., 2000), providing outcomes similar to those reported in the present study.

Further remarkable deductions may be derived by Figure 5. The PCR-DGGE profile of CV6 cheese pro- duced with PM and selected starter culture (Figure $5 \mathrm{~A}$ ) showed the presence of just one band, co-migrating with that of $S$. thermophilus and marked as 2 in the lane SC (starter culture). Bands 1 and 3 in lane SC may be attributed to $L b$. delbrueckii ssp. bulgaricus, identified through the co-migration with $L b$. delbrueckii ssp. bulgaricus isolated from the SC, as in the case of S. thermophilus (data not shown). Band 1 attributable to $L$ b. delbrueckii ssp. bulgaricus was still present in CV0 but disappeared in CV6. Despite a possible under- or overestimation of microbial diversity due to the technique used, the results were at any rate in agreement with those obtained by Gobbetti et al. (2002) and, more recently, by De Pasquale et al. (2014), which highlighted with different methods the low survival of $L b$. delbrueckii ssp. bulgaricus during the ripening of pasta filata cheeses.

The profile of the industrial CV6 (Figure 5A) appeared analogous to that of samples Apu2, PDOBas1, and Mol2 (Figure 2), all characterized by just one band, attributable to $S$. thermophilus. On the other hand, CV6 profiles of cheese produced with RM and NWS (Figure 5B) exhibited a higher complexity, with several bands, many of which derived from microorganisms already present in RM (lane RM) and in NWS (lane NWS).

If that the case, it may be assessed that samples PDOApu1, Bas2, PDOCal1, Cal2, PDOCam1, Cam2,

Table 4. Free amino acid (FAA) content in Caciocavallo cheeses experimentally produced according to the industrial and the artisanal technology, after production (CV0) and after 6 mo of ripening (CV6)

\begin{tabular}{|c|c|c|c|c|}
\hline \multirow{2}{*}{$\begin{array}{l}\text { FAA } \\
(\mathrm{mg} / 100 \mathrm{~g} \text { of } \mathrm{DM})\end{array}$} & \multicolumn{2}{|c|}{ Industrial technology } & \multicolumn{2}{|c|}{ Artisanal technology } \\
\hline & CV0 & CV6 & CV0 & CV6 \\
\hline Aspartic acid & $1.8^{\mathrm{a}}$ & $23.5^{\mathrm{b}}$ & $2.2^{\mathrm{a}}$ & $213.6^{\mathrm{c}}$ \\
\hline Threonine & $0^{\mathrm{a}}$ & $21.7^{\mathrm{b}}$ & $0^{\mathrm{a}}$ & $190.7^{\mathrm{c}}$ \\
\hline Serine & $0.8^{\mathrm{a}}$ & $19.6^{\mathrm{b}}$ & $1.8^{\mathrm{a}}$ & $177.4^{\mathrm{c}}$ \\
\hline Asparagine & $0^{\mathrm{a}}$ & $96.8^{\mathrm{b}}$ & $0^{\mathrm{a}}$ & $364.7^{\mathrm{c}}$ \\
\hline Glutamic acid & $5.0^{\mathrm{a}}$ & $44.8^{\mathrm{b}}$ & $5.1^{\mathrm{a}}$ & $1,083.5^{\mathrm{c}}$ \\
\hline Glutamine & $1.0^{\mathrm{a}}$ & $36.6^{\mathrm{b}}$ & $0^{\mathrm{a}}$ & $175.4^{\mathrm{c}}$ \\
\hline Glycine & $2.6^{\mathrm{a}}$ & $17.6^{\mathrm{b}}$ & $1.0^{\mathrm{a}}$ & $155.1^{\mathrm{c}}$ \\
\hline Alanine & $0^{\mathrm{a}}$ & $33.9^{\mathrm{b}}$ & $0^{\mathrm{a}}$ & $206.0^{\mathrm{c}}$ \\
\hline$\alpha$-Aminobutyric acid & $0^{\mathrm{a}}$ & $0^{\mathrm{a}}$ & $0^{\mathrm{a}}$ & $0^{\mathrm{a}}$ \\
\hline Valine & $1.3^{\mathrm{a}}$ & $91.8^{\mathrm{b}}$ & $2.2^{\mathrm{a}}$ & $524.9^{\mathrm{c}}$ \\
\hline Methionine & $0^{\mathrm{a}}$ & $24.7^{\mathrm{b}}$ & $0^{\mathrm{a}}$ & $197.5^{\mathrm{c}}$ \\
\hline Isoleucine & $0^{\mathrm{a}}$ & $38.9^{\mathrm{b}}$ & $0.3^{\mathrm{a}}$ & $363.8^{\mathrm{c}}$ \\
\hline Leucine & $3.2^{\mathrm{a}}$ & $134.4^{\mathrm{b}}$ & $3.6^{\mathrm{a}}$ & $843.7^{\mathrm{c}}$ \\
\hline Tyrosine & $4.8^{\mathrm{b}}$ & $40.3^{\mathrm{c}}$ & $1.7^{\mathrm{a}}$ & $199.0^{\mathrm{d}}$ \\
\hline Phenylalanine & $5.3^{\mathrm{a}}$ & $117.3^{\mathrm{b}}$ & $5.0^{\mathrm{a}}$ & $494.1^{\mathrm{c}}$ \\
\hline$\beta$-Amino butyric acid & $0^{\mathrm{a}}$ & $97.2^{\mathrm{c}}$ & $0^{\mathrm{a}}$ & $10.3^{\mathrm{b}}$ \\
\hline Ornithine & $0^{\mathrm{a}}$ & $118.1^{\mathrm{b}}$ & $0^{\mathrm{a}}$ & $164.7^{\mathrm{c}}$ \\
\hline Lysine & $7.3^{\mathrm{a}}$ & $70.0^{\mathrm{b}}$ & $8.4^{\mathrm{a}}$ & $778.9^{\mathrm{c}}$ \\
\hline Histidine & $3.4^{\mathrm{a}}$ & $4.5^{\mathrm{b}}$ & $4.3^{\mathrm{a}}$ & $262.8^{\mathrm{c}}$ \\
\hline Arginine & $3.1^{\mathrm{a}}$ & $26.1^{\mathrm{b}}$ & $5.9^{\mathrm{a}}$ & $119.7^{\mathrm{c}}$ \\
\hline Proline & $0^{\mathrm{a}}$ & $130.4^{\mathrm{b}}$ & $0^{\mathrm{a}}$ & $997.9^{\mathrm{c}}$ \\
\hline Total & $39.6^{\mathrm{a}}$ & $1,188.2^{\mathrm{b}}$ & $41.5^{\mathrm{a}}$ & $7,523.67^{\circ}$ \\
\hline
\end{tabular}

${ }^{\mathrm{a}-\mathrm{d}}$ Means within a row with different superscripts differ $(P<0.05)$. 


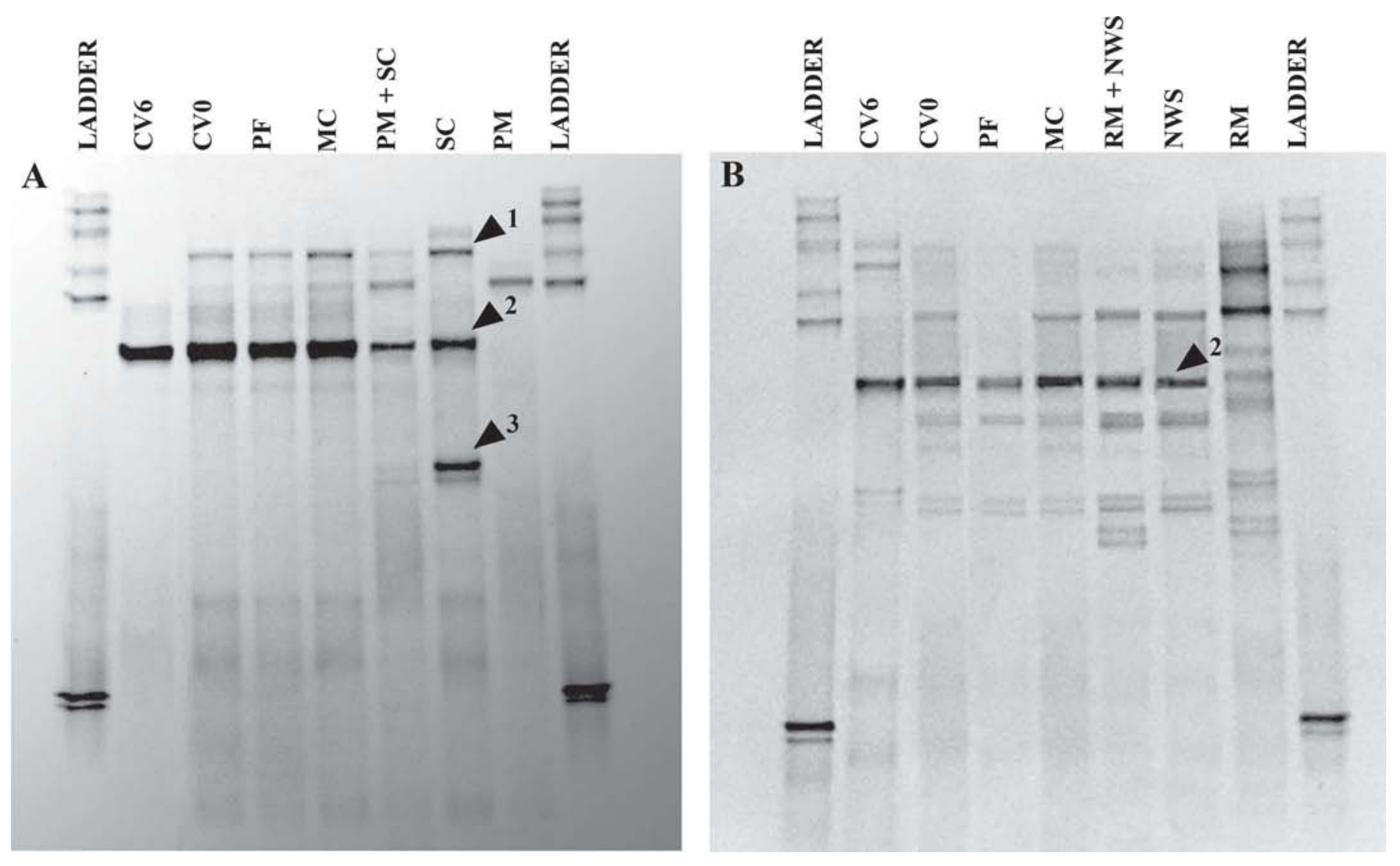

Figure 5. Polymerase chain reaction-denaturing gradient gel electrophoresis of V1 16S rDNA region in samples collected during experimental cheese-making performed according to (A) industrial and (B) artisanal technologies. RM = raw milk; PM = pasteurized milk; NWS = natural whey starter; $\mathrm{SC}=$ commercial starter culture; RM+NWS = bulk milk with NWS added; PM+SC = pasteurized milk with SC added; MC = mature curd; $\mathrm{PF}=$ pasta filata; CV0 = cheese after brining; CV6 = cheese after 6 mo of ripening. Bands 1 and 3 correspond to Lactobacillus delbrueckii ssp. bulgaricus; band 2 corresponds to Streptococcus thermophilus.

Cam3, and Mol1 showed the typical complex DGGE profile (Figure 2) of the artisanal Caciocavallo cheese (Figure 5B). Remarkably, the band corresponding to $S$. thermophilus was retrieved in each analyzed sample during the manufacture of the artisanal Caciocavallo cheeses, except in RM (Figure 5B). Indeed, the same result was obtained by Mangia et al. (2016), that highlighted, through a polyphasic approach, the presence of $S$. thermophilus in curd and in Casizolu pasta filata cheese but not in milk samples.

Our data confirm those obtained by Ercolini et al. (2008), who analyzed the microbial diversity of NWS for Caciocavallo Silano cheese. In fact, the authors found in many analyzed samples only a few species, mainly Lb. delbrueckii, Lactobacillus helveticus, and $S$. thermophilus. These thermophilic species could be selected during the thermization of milk (up to $58^{\circ} \mathrm{C}$ for $30 \mathrm{~s}$ ), which can be adopted during the production of PDO Caciocavallo cheese, or, arguably, during the stretching. During the ripening, other mesophilic/ thermotolerant nonstarter LAB, principally deriving from RM, may take over and thus be found in the final products (Corsetti et al., 2001; Gobbetti et al., 2002; Coppola et al., 2003; Piraino et al., 2005).

This microbial progression was clearly proven in the artisanal production (Figure 5B), whereas it was missing in the industrial one (Figure 5A).

\section{CONCLUSIONS}

According to reported results, a high variability in both physico-chemical and microbiological features characterized long ripened PDO Caciocavallo Silano and non-PDO Caciocavallo cheeses. The unique consistency was given by culture-independent PCR-DGGE analysis, which allowed to individuate in all samples one band corresponding to $S$. thermophilus, while all other analyzed parameters varied. The experimental productions of Caciocavallo cheeses provided several important benchmarks, above all when 6 mo ripened 
cheeses were compared with those collected in the first part of the survey. In fact, out of 11 PDO and non-PDO analyzed cheeses, 8 showed features comparable with experimentally manufactured artisanal Caciocavallo cheeses, as evidenced by higher values of total FAA and by complex PCR-DGGE profiles. On the other hand, 1 PDO Caciocavallo Silano and 2 non-PDO cheeses showed total FAA and PCR-DGGE profiles similar to those of experimental Caciocavallo produced following the industrial technology. Data obtained in our study suggest the use of PM in different dairy plants located in the PDO geographical area. This fact does not represent a problem per se for non-PDO cheeses, even if all producers declared to follow the artisanal technology, but it may represent a bad practice in the case of PDO Caciocavallo Silano cheese, whose production regulation does not allow milk pasteurization.

\section{ACKNOWLEDGMENTS}

The authors report no conflict of interest.

\section{REFERENCES}

Albenzio, M., A. Santillo, D. E. Russo, M. Caroprese, R. Marino, and A. Sevi. 2010. Influence of milk quality and production protocol on proteolysis and lipolysis in Monti Dauni Meridionali Caciocavallo cheese. J. Dairy Res. 77:385-391.

AOAC International. 2000. Official Methods of Analysis. 17th ed. AOAC International, Arlington, VA.

Aponte, M., V. Fusco, R. Andolfi, and S. Coppola. 2008. Lactic acid bacteria occurring during manufacture and ripening of Provolone del Monaco cheese: Detection by different analytical approaches. Int. Dairy J. 18:403-413.

Aydemir, O., H. Harth, S. Weckx, M. Dervisoğlu, and L. De Vuyst. 2015. Microbial communities involved in Kașar cheese ripening. Food Microbiol. 46:587-595.

Bütikofer, U., and Y. Ardö. 1999. Quantitative determination of free amino acids in cheese. Pages 24-32 in Chemical Methods for the Evaluating Proteolysis in Cheese Maturation. Part 2. Int. Dairy Federation Bulletin 337/1100BEF

Cocolin, L., M. Manzano, D. Aggio, C. Cantoni, and G. Comi. 2001. A novel polymerase chain reaction (PCR) - denaturing gradient gel electrophoresis (DGGE) for the identification of Micrococcaceae strains involved in meat fermentations. Its application to naturally fermented Italian sausages. Meat Sci. 58:59-64.

Coppola, R., M. Nanni, M. Iorizzo, A. Sorrentino, E. Sorrentino, C. Chiavari, and L. Grazia. 2000. Microbiological characteristics of Parmigiano Reggiano cheese during the cheesemaking and the first months of the ripening. Lait 80:479-480.

Coppola, R., M. Nanni, M. Succi, A. Sorrentino, M. Iorizzo, C. Chiavari, and L. Grazia. 2001. Enumeration of thermophilic lactic acid bacteria in ripened cheeses manufactured from raw milk. Milchwissenschaft 56:140-142.

Coppola, R., M. Succi, E. Sorrentino, M. Iorizzo, and L. Grazia. 2003. Survey of lactic acid bacteria during the ripening of Caciocavallo cheese produced in Molise. Lait 83:211-222.

Corsetti, A., M. R. Corbo, M. Albenzio, R. Di Cagno, M. Gobbetti, and P. F. Fox. 2001. Microbiology and biochemistry of Caciocavallo Silano cheese. Ital. J. Food Sci. 13:297-309.

De Pasquale, I., R. Di Cagno, S. Buchin, M. De Angelis, and M. Gobbetti. 2014. Microbial ecology dynamics reveal a succession in the core microbiota involved in the ripening of pasta filata Caciocavallo Pugliese cheese. Appl. Environ. Microbiol. 80:6243-6255.

Di Cagno, R., I. De Pasquale, M. De Angelis, and M. Gobbetti. 2012. Accelerated ripening of Caciocavallo Pugliese cheese with attenuated adjuncts of selected nonstarter lactobacilli. J. Dairy Sci. 95:4784-4795.

Egger, L., M. Nicolas, and L. Pellegrino. 2016. Alkaline phosphatase activity in cheese as a tracer for cheese milk pasteurization. LWT Food Sci. Technol. (Campinas) 65:963-968.

Ercolini, D., G. Frisso, G. Mauriello, F. Salvatore, and S. Coppola. 2008. Microbial diversity in natural whey cultures used for the production of Caciocavallo Silano PDO cheese. Int. J. Food Microbiol. 124:164-170.

EU (European Union). 1996. Regulation (EC) No.1263/96 of 1 July 1996 supplementing the Annex to Regulation (EC) No. 1107/96 on the registration of geographical indications and designations of origin under the procedure laid down in Article 17 of Regulation (EC) No. 2081/92. Official Journal L 163, 02.07.1996.

EU (European Union). 2003. Regulation (EC) No. 1204/2003 amending the specifications of three names appearing in the Annex to Regulation (EC) No. 1107/96 (Roncal, Noix de Grenoble and Caciocavallo Silano). Official Journal L 168, 05.07.2003.

Frau, M., J. Massanet, C. Rosselló, S. Simal, and J. Canëllas. 1997. Evolution of free amino acid content during ripening of Mahón cheese. Food Chem. 60:651-657.

Gobbetti, M., M. De Angelis, R. Di Cagno, L. Mancini, and P. F. Fox. 2015. Pros and cons for using non-starter lactic acid bacteria (NSLAB) as secondary/adjunct starters for cheese ripening. Trends Food Sci. Technol. 45:167-178.

Gobbetti, M., M. Morea, F. Baruzzi, M. R. Corbo, A. Matarante, T. Considine, R. Di Cagno, T. Guinee, and P. F. Fox. 2002. Microbiological, compositional, biochemical and textural characterisation of Caciocavallo Pugliese cheese during ripening. Int. Dairy J. $12: 511-523$.

Grappin, R., and E. Beuvier. 1997. Possible implications of milk pasteurization on the manufacture and sensory quality of ripened cheese. Int. Dairy J. 7:751-761.

Iacumin, L., F. Cecchini, M. Manzano, M. Osualdini, D. Boscolo, S. Orlic, and G. Comi. 2009. Description of the microflora of sourdoughs by culture-dependent and culture-independent methods. Food Microbiol. 26:128-135.

Mangia, N. P., F. Fancello, and P. Deiana. 2016. Microbiological characterization using combined culture dependent and independent approaches of Casizolu pasta filata cheese. J. Appl. Microbiol. 120:329-345.

Marotta, M., M. De Rosa, K. N. Kilcawley, E. M. Sheenan, C. M. Delahunty, T. Uniacke-Lowe, and P. F. Fox. 2007. Comparative study on Caciocavallo Campano cheese. Ital. J. Food Sci. 19:263-278.

Mincione, B., A. Caridi, and S. Fuda. 1996. Caciocavallo Silano. Pages 67-70 in I prodotti caseari del Mezzogiorno - Caratterizzazione analitica e compositiva. P. Lembo, ed. Grafiche Vadacca, Milano, Italy.

Morea, M., A. Matarante, R. Di Cagno, F. Baruzzi, and F. Minervini. 2007. Contribution of autochthonous non-starter lactobacilli to proteolysis in Caciocavallo Pugliese cheese. Int. Dairy J. 17:525534.

Mucchetti, G., and E. Neviani. 2006. Microbiologia e tecnologia lattiero-casearia. Tecniche nuove, Milano, Italy.

Niro, S., A. Fratianni, R. Mignogna, P. Tremonte, E. Sorrentino, and G. Panfili. 2012. An innovative pre-ripening drying method to improve the quality of pasta filata cheeses. J. Dairy Res. 79:397-404.

Niro, S., A. Fratianni, P. Tremonte, E. Sorrentino, L. Tipaldi, G. Panfili, and R. Coppola. 2014. Innovative Caciocavallo cheeses made from a mixture of cow milk with ewe or goat milk. J. Dairy Sci. 97:1296-1304

Parente, E., M. A. Rota, A. Ricciardi, and F. Clementi. 1997. Characterization of natural starter culture used in the manufacture of pasta-filata cheese in Basilicata (Southern Italy). Int. Dairy J. 7:775-783

Piraino, P., T. Zotta, A. Ricciardi, P. L. H. McSweeney, and E. Parente. 2008. Acid production, proteolysis, autolytic and inhibitory 
properties of lactic acid bacteria isolated from pasta filata cheeses: A multivariate screening study. Int. Dairy J. 18:81-92.

Piraino, P., T. Zotta, A. Ricciardi, and E. Parente. 2005. Discrimination of commercial Caciocavallo cheeses on the basis of the diversity of lactic microflora and primary proteolysis. Int. Dairy J. 15:1138-1149.

Rantsiou, K., E. H. Drosinos, M. Gialitaki, R. Urso, J. Krommer, J. Gasparik-Reichardt, S. Tóth, I. Metaxopoulos, G. Comi, and L. Cocolin. 2005. Molecular characterization of Lactobacillus species isolated from naturally fermented sausages produced in Greece, Hungary and Italy. Food Microbiol. 22:19-28.

Reale, A., T. Di Renzo, M. Succi, P. Tremonte, R. Coppola, and E. Sorrentino. 2013. Microbiological and fermentative properties of baker's yeast starter used in breadmaking. J. Food Sci. 78:M1224M1231.
Rehman, S. U., P. L. H. McSweeney, J. M. Banks, E. Y. Brechany, D. D. Muir, and P. F. Fox. 2000. Ripening of Cheddar cheese made from blends of raw and pasteurised milk. Int. Dairy J. 10:33-44.

Sheffield, V. C., D. R. Cox, L. S. Lerman, and R. M. Myers. 1989. Attachment of a 40-base pairs GC rich sequence (GC clamp) to genomic DNA fragments by the Polymerase Chain Reaction results in improved detection of single-base changes. Proc. Natl. Acad. Sci. USA 86:232-236.

Sorrentino, E., L. Tipaldi, G. Pannella, G. La Fianza, M. Succi, and P. Tremonte. 2013. Influence of ripening conditions on Scamorza cheese quality. Int. J. Agric. Biol. Eng. 6:71-79.

Succi, M., E. Sorrentino, T. Di Renzo, P. Tremonte, A. Reale, L. Tipaldi, G. Pannella, A. Russo, and R. Coppola. 2014. Lactic acid bacteria in pharmaceutical formulations: Presence and viability of "healthy microorganisms". J. Pharm. Nutr. Sci. 4:66-75. 